\title{
Como a familia pode estimular a criança com microcefalia?
}

A microcefalia é uma doença congênita que impede o crescimento normal do crânio da criança, quando comparadas a outras de mesma idade e sexo. Esta doença cursa com crescimento insuficiente do cérebro, o que pode evoluir com diversas sequelas, como atraso do desenvolvimento neuropsicomotor, dificuldade visual e auditiva, atraso mental, retardo na função motora seguido de disfunção da sensibilidade, fala, concepção e comportamento, hiperatividade, déficits de equilíbrio e coordenação, alterações faciais e respiratórias, acarretando em transtornos musculoesqueléticos como deformações e contraturas. A família não estava preparada para lidar com um bebê com microcefalia e experimentará sentimentos de incerteza sobre a doença, sobrevivência, e futuro da criança, além da mudança da rotina e dinâmica familiar; dependência de tratamentos e assistência de outras pessoas ou familiares. A criança necessitará ser acompanhada por uma equipe multiprofissional e orientada a estimular o desenvolvimento e prevenir alterações e comprometimentos importantes no desenvolvimento neuropsicomotor. Para isso, precisará receber muito apoio e orientação sobre estimulação e domiciliares. O objetivo deste estudo é realizar uma revisão bibliográfica para levantar as estratégias que podem ser usadas pela família para potencializar o desenvolvimento da criança com microcefalia. 0 estudo caracteriza-se como revisão bibliográfica, baseado em documentos governamentais e análise de artigos científicos publicados entre 2008 e 2018 , através de consultas documentos governamentais e bases de dados on-line como SciELO, LILACS e Google Acadêmico entre fevereiro e abril de 2018, protagonizando as palavras-chave 'microcefalia', 'estimulação precoce', 'família', 'criança' e 'desenvolvimento infantil'. É de fundamental importância a articulação da família na extensão do seu domicílio para complementar as ações do fisioterapeuta e demais profissionais que acompanha esta criança. A família deve ter ação ativa na estimulação precoce da criança com microcefalia, através de estímulos táteis, auditivos, visuais, proprioceptivos, vestibulares, motores, e também ser encorajada a integrar-se a grupos de apoio à família, a fim de romper as barreiras do medo, angústia e da informação acerca do contexto que envolve seu filho.

Palavras-chave: Microcefalia; Estimulação Precoce; Família; Criança; Desenvolvimento Infantil.

\section{How can a family stimulate a child with microcephaly?}

Microcephaly is a congenital disease that prevents the normal growth of the child's skull when compared to others of the same age and sex. This disease presents with insufficient growth of the brain, which can evolve with several sequels, such as delayed neuropsychomotor development, visual and auditory difficulty, mental retardation, delayed motor function followed by sensitivity dysfunction, speech, conception and behavior, hyperactivity, deficits balance and coordination, facia and respiratory changes, leading to musculoskeletal disorders such as deformations and contractures. The family was not prepared to deal with a baby with microcephaly and will experience feelings of uncertainty about the child's illness, survival, and future, as well as changing routine and family dynamics; dependence on care and assistance from other people or family members. The child will need to be accompanied by a multiprofessional team and oriented to stimulate the development and to prevent important alterations and commitments in neuropsychomotor development. To do this, you will need to receive a lot of support and guidance on stimulation and domiciliary. The objective of this study is to perform a literature review to identify the strategies that can be used by the family to enhance the development of the child with microcephaly. The study is characterized as a bibliographic review, based on governmental documents and analysis of scientific articles published between 2008 and 2018, through consultations with government documents and on-line databases such as SciELO, LILACS and Google Scholar between February and April 2018, with the key words 'microcephaly', 'early stimulation', 'family', 'child' and 'child development'. It is of fundamenta importance the articulation of the family in the extension of their domicile to complement the actions of the physiotherapist and other professionals who accompany this child. The family should have active action in the early stimulation of the child with microcephaly through tactile, auditory, visual, proprioceptive, vestibular, motor stimuli, and also be encouraged to join family support groups in order to break the barriers fear, anguish, and information about the context surrounding your child.

Keywords: Microcephaly; Early Stimulation; Family; Kid; Child development.

Topic: Fisioterapia

Reviewed anonymously in the process of blind peer.

Daniela Maristane Vieira Lopes Maciel (iD)

Faculdade Guaraí, Brasil

http://lattes.cnpq.br/0591590391105455

http://orcid.org/0000-0001-5934-0219

daniela.marciel@iescfag.edu.br

Stefhanne Lorrane Silva Parente

Faculdade Guaraí, Brasil

http://lattes.cnpq.br/0354240636601860

stefhanneparente@hotmail.com

Layena Alice Bento de Sousa Oliveira

Faculdade Guaraí, Brasil

layenaalice@hotmail.com
Received: 05/08/2019

Approved: 17/08/2019

\section{Referencing this:}

MACIEL, D. M. V. L.; PARENTE, S. L. S.; OLIVEIRA, L. A. B. S.. Como a família pode estimular a criança com microcefalia?. Scire Salutis, v.8, n.2, p.24-31, 2018. DOI: http://doi.org/10.6008/CBPC22369600.2018.002.0003 


\section{INTRODUÇÃO}

O desenvolvimento infantil pode ser determinado como um procedimento integral e multidimensional, que inicia na concepção e integra o crescimento físico, o desenvolvimento comportamental, cognitivo, sensorial, linguagem e a maturação neurológica, tal como as relações socioafetivas, tornando a criança capacitada a responder suas necessidades e as do seu meio. Entre as condições biológicas de risco para um desenvolvimento infantil adequado estão: prematuridade, hemorragia intraperiventricular, displasia broncopulmonar, asfixia perinatal, microcefalia, entre outros (BRASIL, 2016).

A microcefalia é uma doença congênita que impede o crescimento normal do crânio da criança, quando comparadas a outras de mesma idade e sexo que cursam com crescimento insuficiente do cérebro (SÁ, 2013; ONU, 2016). A maior parte das ocorrências de microcefalia são seguidas de alterações motoras e cognitivas, as quais alteram de acordo com grau de agressão cerebral (BRASIL, 2016). Ela pode ser classificada de duas formas: microcefalia congênita, que está evidente ao nascimento; e microcefalia pós-natal, quando há falha no desenvolvimento natural do perímetro cefálico após o nascimento (NORBERT et al., 2016).

Existem diversos fatores relacionados à microcefalia, podendo ir desde a desnutrição da mãe, excesso de drogas a contaminações no decorrer da gestação como citomegalovírus, toxoplasmose e rubéola. Diversas anomalias, síndromes metabólicas ou genéticas, abusos ambientais e motivos desconhecidos são capazes de lesar o crescimento do cérebro e agregar-se à patologia. A infecção materna pelo Zika Vírus (ZIKAV) contaminado pelo Aedes aegypti é responsável recentemente pelo epidemia de microcefalia no Brasil (REIS, 2015).

As consequências da microcefalia vão decorrer de sua origem e da idade que aconteceu o caso, visto que, quanto mais a doença for precoce, mais complicadas serão as lesões do Sistema Nervoso Central (SNC). A microcefalia expõe-se de diferentes alterações, tornando-se as mais constantes o atraso do desenvolvimento neuropsicomotor, paralisia cerebral, dificuldade de deglutição, epilepsia, irregularidades dos sistemas auditivo e visual, como também distúrbio do comportamento (TDAH e autismos) (EICKMANN et al., 2016). Depois de a criança ser diagnosticada e clinicamente equilibrada, métodos de intervenção precoce necessitam ser estabelecidos, com finalidade de minimizar e prevenir deformidades (NORBERT et al., 2016).

O vírus Zika é da família dos flavivírus, e foi isolado pela primeira vez em macacos em Uganda, no ano de 1947. A infecção humana foi confirmada pela primeira vez em 1953 na Nigéria. Em 2007 houve, na Micronésia, o aparecimento de uma epidemia (primeira fora da África e Ásia), e entre 2013 e 2014 surgiu uma epidemia também na Polinésia Francesa e em outras ilhas do Pacífico Sul (ABREU et al., 2017).

No Brasil, o vírus foi detectado pela primeira vez em maio de 2015 com o primeiro surto na Região Nordeste. A partir de 29 de janeiro de 2016, a transmissão local foi detectada em pelo menos em 22 países ou territórios, sendo o primeiro a ter uma associação entre o vírus e a complicação grave de recém-nascidos com microcefalia (SÁ et al., 2016). Após o início do surto do Zika, foi constatado um aumento do número de casos de recém-nascidos com microcefalia no Brasil, sendo 1.248 novos casos suspeitos no ano de 2015 , o que representou um salto de vinte vezes em relação aos últimos anos (FLOR et al., 2017). 
Quando um bebê com comprometimentos graves nasce, ou no caso de a criança apresentar microcefalia, ocorre um impacto significativo na vida dos pais, que esperavam uma criança diferente daquela que nasceu. Por consequência, as figuras parentais e outros familiares próximos acabam por enfrentar angústias e uma gama de sentimentos contraditórios. Há sentimentos de incerteza quanto à sobrevivência e desenvolvimento da criança e desconhecimento sobre a doença e os cuidados que terá que realizar, além do sentimento de culpa, impotência e dependência de terceiros. Tal contexto tem potencial para gerar angústia, ansiedade e estresse aos cuidadores principais, nem sempre centradas nas representações materna e paterna originais, aquelas sobre o filho imaginado e desejado (FORMIGA et al., 2010; NORBERT et al., 2016).

Para corresponder a esta nova demanda a família deverá receber muito apoio e orientação. Uma das estratégias é ser acompanhada pelo fisioterapeuta e iniciar uma intervenção precoce englobando regiões sensoriais (olfativa, visual, tátil, auditiva, cinestésica, vestibular e proprioceptiva), sem submeter à percepção natural da maturidade do SNC, possibilitando assim o desenvolvimento completo da criança e sua capacidade neuropsicomotora. Quanto mais precoce for a intervenção, mais chances um cérebro imaturo e em crescimento terá de adquirir sensações naturais e de assumir elas corretamente ao longo do seu desenvolvimento (DEFILLIPO et al., 2012; RABELO et al., 2016).

Programas destinados à saúde infantil devem estar voltados para o ambiente em que a criança vive, pois é nele que ela se estrutura como um ser individual e social. Diante disso, o papel da família é sem dúvida de suma importância no tratamento complementar da criança com microcefalia, principalmente nas conquistas que terá no decorrer de sua vida (NORBERT et al., 2016).

Muitos estudos versam sobre a estimulação da criança com microcefalia pela equipe multiprofissional, mais poucos abordam a importância da família neste contexto. Com isso, o objetivo desse estudo é realizar uma revisão bibliográfica para levantar as estratégias que podem ser usadas pela família para potencializar o desenvolvimento da criança com microcefalia.

\section{METODOLOGIA}

O estudo se caracteriza como revisão bibliográfica, baseado em documentos governamentais nacionais e internacionais e análise de artigos científicos publicados entre 2008 e 2018. Para isso, foram consultadas bases de dados on-line como SciELO, LILACS e Google Acadêmico entre fevereiro e abril de 2018. Os Descritores em Ciências da Saúde (DCS) protagonizados foram 'Microcefalia', 'Estimulação Precoce', 'Família', 'Criança' e 'Desenvolvimento Infantil'.

\section{DISCUSSÃO TEÓRICA}

Quando uma criança com microcefalia nasce, tem início uma rotina de exames para determinar qual o tipo de malformação elas têm, qual o nível de comprometimento do cérebro, da visão, da audição, entre outros. Além disso, os bebês diagnosticados ou com suspeita de microcefalia são submetidos desde os primeiros meses de vida a intervenções de várias áreas, como fisioterapia, fonoaudiologia, otorrinolaringologia e oftalmologia, até porque a extensão das restrições neurológicas e musculoesqueléticas 
são desconhecidas e iram se manifestar ao longo do tempo. No intuito de agir preventivamente nos atrasos neuroevolutivos é preciso intervir precocemente na janela biológica de até três anos de idade, a fim de reduzir portanto, o nível de comprometimento causado pela malformação (BRASIL, 2017).

A intervenção precoce pelo fisioterapeuta deve ser intensificada até três anos de idade, pois esta é a fase em que o cérebro se desenvolve de forma mais rápida, abrindo janelas de oportunidades para o estabelecimento das fundações que refletirão em uma boa saúde e produtividade no futuro. Isto não quer dizer que ela seja interrompida após este período (BRASIL, 2016).

O desenvolvimento motor segue uma ordem cronológica evolutiva com etapas distintas e previsíveis, caracterizadas por mudanças nas habilidades e nos padrões de movimento que ocorrem durante a vida. No entanto, este desenvolvimento pode sofre interferências de fatores no pré, peri e pós-parto, repercutindo com alterações na aquisição de habilidades motoras, cognitivas e psicossociais, causando limitações nas aquisições neurofuncionais, interferindo nas tarefas de autocuidado como alimentação e banho independentes, atividades de mobilidade como levantar da cama e ir ao banheiro com independência, além de tarefas de função social como ir à escola e interagir com outras crianças (HALLAL et al., 2008).

A microcefalia pode causar diversas alterações na criança, como atraso do desenvolvimento neuropsicomotor em decorrência da desaceleração no crescimento do cérebro, dificuldade visual e auditiva, atraso mental, retardo na função motora seguido de disfunção da sensibilidade, fala, concepção e comportamento, hiperatividade, déficits de equilíbrio e coordenação, alterações faciais e respiratórias, acarretando transtornos musculoesqueléticos como deformações e contraturas (DIAS et al., 2017; FLORIANI, 2017).

A chegada de uma criança interfere em toda a rotina da família, muitas vezes envolvendo sentimentos como angustia, ansiedade, medo e insegurança. Esses sentimentos podem se tornar mais intensos quando a criança apresenta alguma deficiência. Preocupações em relação à sobrevida e ao futuro dessas crianças, sensação de culpa, ineficácia, dependência e acima de tudo o desconhecimento de como cuidar, trazem enormes transtornos a essa família, tornando necessário a atenção das equipes de saúde e o apoio psicossocial mais específico a essas famílias (BRASIL, 2017).

A Organização Mundial da Saúde (OMS), propõe incentivar o desenvolvimento da criança com microcefalia para amenizar as sequelas neurológicas desencadeadas pela doença. O primeiro ano de idade é a fase mais favorável ao desenvolvimento da neuroplasticidade cerebral, é um estágio de crescentes transformações e crescimento das redes neuronais. Por isso, é fundamental que a família ofereça estímulos por meio de tarefas do dia a dia e brincadeiras lúdicas, ou seja, além do acompanhamento com a equipe multiprofissional, é necessário o envolvimento da família (FLORIANI, 2017).

Para isso, o âmbito familiar necessita ser estimulante, a cada troca de trajes, troca de posicionamento, banho, oferta de brinquedos, deve ser auxiliado de estímulos táteis e verbais. 0 bebê precisa estar sempre junto dos pais, protetores sempre que provável, durante o trabalho, dialogando, brincando ou se alimentando. Sempre participando da dinâmica do domicílio (NORBERT et al., 2016). As causas psicoafetivas oferecem auxílios para todo o procedimento de recuperação, é evidente o fato da 
qualidade e quantidade de estímulos obtidos pela criança em sua residência serem fundamental (SARI et al., 2008).

Através do brincar e das atividades do dia a dia, a criança aumenta o desempenho afetivo, motor, sensorial e cognitivo e a curiosidade do mundo em sua volta. Para que pais explore mais seu bebê, devem utilizar-se um espaço agradável e calmo, organizando uma rotina com várias dinâmicas para que ambos efetuem (UNICEF, 2017).

As estratégias utilizadas pela família exercem um papel de suporte complementar ao desenvolvimento da criança com microcefalia devem ser exercidas numa perspectiva global atuando desde a estimulação auditiva, linguagem, visual, vestibular e proprioceptivo, tátil, motora, até mesmo a inclusão e participação de familiares em grupos de apoio.

\section{Estimulação auditiva e da linguagem}

A estimulação da audição inicia com a excitação da mente, por meio da concentração e repetição de sons lúdicos, possibilitando a criança a emitir diversos e ricos barulhos, que irá contribuir para possíveis entendimentos da linguagem (BRASIL, 2016). A criança precisa ser estimulada progressivamente para melhorar suas habilidades auditivas através de estímulos com objetos sonoros, a exemplo de chocalhos, sinos, teclado musical e sons de diferentes animais. A família deve ser sempre o meio de ensinamento, estar se comunicando constantemente com o bebê, cantando e contando histórias fazendo com que gire a cabeça em direção ao sons emitido (BRASIL, 2017).

No decorrer do dia, a família deve apreciar ações que incentiva a audição: estalos de dedos e língua, sons de risadas, barulhos de beijos e aplausos. Os sons devem ser efetuados em várias direções fazendo com que o bebê busque a direção dos ruídos, esperar a resposta da criança sempre quando for executar a seguintes tarefas. Quando os pais forem realizar alguma atividade devem conversar com a criança, falando o que deseja efetuar com ela. A linguagem pode ser estimulada com as vogais demorada: 'aaaa'; 'eee'; 'iiii'; 'ooo'; 'uuu'; 'ãooo'; repetir sílabas como 'tutu'; 'caca'; 'papa'; 'pipi'; 'mama'; 'xixi'; 'baba'. Os cuidadores devem usar curtos termos, com: 'Vamos brincar'; 'Vamos cantar'; dentre outras. A família deve pronunciar as palavras de forma correta, evitando infantilizá-la como 'brincadeirinha-brincadeira'; 'bolinha-bola'; 'dedeira-mamadeira'; 'princesinha-princesa'; etc. (UNICEF, 2017).

\section{Estimulação Visual}

A estimulação visual da criança pode ser realizada através do brincar. Os pais podem estar utilizando objetos grandes e coloridos mantendo uma distância de aproximadamente $20 \mathrm{~cm}$ do bebê. Os brinquedos precisam ser posicionados a frente da criança em sua linha média, fazendo sempre lentos movimentos em seu meio visual para que o observe (BRASIL, 2016).

O período mais adequado para a família realizar dinâmicas visuais de auxílio ao progresso da criança é no momento em que estiver ativa e calma. É sugerido estimuladores brilhantes ou a claridade natural do ambiente, mas é preciso prevenir a luminosidade diretamente nos olhos, especialmente as que manifestem 
problemas convulsivas. Para ampliar o contraste e reduzir a distração do bebê no período da estimulação, pode ser utilizado fundo escuro. Os objetos coloridos precisam ser colocados sobre um tecido liso para dar mais contraste (BRASIL, 2017; UNICEF, 2017).

\section{Estimulação Tátil}

A estimulação tátil da criança pode ser trabalhada de diversas formas, e para que isso aconteça, a família precisa incentivá-la, fazendo com que explore e desenvolva o tato. É preciso que o cuidador faça com que ela sinta objetos com variados tamanhos, formas e texturas como algodão, espuma de barbear, geleia, grama, areia e terra tintas, massinhas, grãos de feijão, e farinhas. Essas diferentes sensações experienciadas vão ajudá-la a diferenciar e trabalhar seu desenvolvimento neuropsicomotor (NORBET et al., 2016).

\section{Estimulação Vestibular e Proprioceptiva}

Para oferecer estímulos vestibulares e proprioceptivos a criança, a família precisa promover atividades para treinar o equilíbrio e percepção e localização das partes do corpo no espaço. Há várias formas de incentivar o bebê, como sentar o bebê no colo movimentando as pernas para que ele se mova lateralmente, sentada no colchonete ou no chão posicionando o brinquedo a frente da criança para tentar pegá-lo, afim de trabalhar sua reação de proteção, utilizar instrumentos como cavalinho 'upa upa', bola, balanço, superfícies estável e instável, caminhar em areia vencendo obstáculos (REIS et al., 2018).

\section{Estimulação Motora}

Para que os pais trabalhem a parte motora da criança, é preciso fazer com que ela se movimente e perceba seu lugar no ambiente e sua existência corporal. A mobilidade precisa ser trabalhada e adaptada em diferentes movimentos para favorecer o tônus e a força dos músculos. É importante priorizar a parte do corpo mais acometida, trabalhando com o alongamento, estimulação e massagens relaxantes. A criança não pode ser forçada e nem entediada, pois nessa relação é indispensável ter conhecimento de seus deveres e da medida adequada de estímulos para suprir suas necessidades (BRASIL, 2016).

Com objetivo de incentivar o equilíbrio cefálico, o cuidador pode estar posicionando o bebê em decúbito ventral apoiado sobre um rolo, em sua coxa ou acima de seu abdômen, sempre utilizando brinquedos e fazendo estímulos para que levante e sustente a cabeça. Para promover o rolar da criança, deve-se posicioná-la em decúbito dorsal colocando o braço ao lado do corpo, dando impulsos no quadril ou utilizando brinquedos para chamar sua atenção, fazendo com que se vire sozinho (UNICEF, 2017).

Para promover o sentar da criança, ela precisa ter força muscular da cervical e abdômen; a mãe pode estar posicionando-a em seu colo ou encostada em travesseiros, ofertando brinquedos à sua vista para que ela possa pega- ló. Deve-se colocá-la em decúbito dorsal segurando os seus braços, levantando lentamente realizando uma flexão de tronco. À medida que seu abdômen for se tornando mais forte, os pais precisam sentá-la sem suporte dorsal, não deixando sem cuidados até que ela consiga sentar sozinha (BRASIL, 2017). 
Para fortalecer os músculos do ombro, a criança deve ser colocada sobre a bola, rolo ou apoiada em sua própria coxa, fazendo com que descarregue a força sobre as mãos. Os pais podem também estar utilizando lençol e toalhas em volta de seu abdômen, proporcionando o descarregamento da força exata nos membros, não esquecendo de colocar um brinquedo à sua frente fazendo com que se mova realizando a dissociação escapular e pélvica favorecendo o engatinhar (BRASIL, 2016).

Para que a criança desenvolva o caminhar ela precisa ter sustento cefálico, de tronco, força de abdômen, quadril e membros inferiores resistente para sustentar o peso do próprio corpo. Embora a criança não seja apta a andar, é importante que estimulem a posição em pé, com o objetivo de fortalecer os ossos descarregando o peso nas pernas. Há diversas maneiras da família estimular a marcha com apoio e a marcha independente. $\mathrm{O}$ cuidador pode estar segurando o corpo da criança estimulando a ficar de pé.

Posicione os brinquedos à sua vista, fazendo com que ela levante a cabeça e tente agarrá-los com as mãos. Coloque os braços apoiada sobre a bola, rolo ou cadeira, calmamente empurre o objeto para frente, com a finalidade de mover o quadril e as pernas. Os pais podem estar segurando a criança pelas as mãos ou no quadril, procurando chamar sua atenção com brinquedos e estímulos verbais induzindo a caminhar até ela se sentir confiante para realizar a marcha independente (FLOR, 2011 e BRASIL, 2017).

\section{Família inserida em grupos de apoio a crianças com microcefalia}

A equipe multiprofissional deve incentivar as mulheres a se envolverem e a convidarem uma pessoa de confiança (companheiro, familiar ou amigo) para participar de sessões de acompanhamento junto a grupos de apoio à criança com microcefalia. O profissional deve discutir e detalhar a necessidade da mãe ou responsável a decidir de que forma querem fortalecer seu suporte social, por exemplo, conversando com alguém, obtendo ajuda mais prática, tal como ajuda para cuidar de outras crianças da família, realizar tarefas rotineiras ou conectar-se a outras organizações, ou comunidades. Pode também ser auxiliada a identificar membros da família, amigos e membros da comunidade confiáveis e solidários e pensar sobre como cada um pode estar envolvido em ajudar (ONU, 2016).

Os grupos de apoio à família auxiliam os pais a enfrentar as emoções e fortalecer as relações afetivas. O conhecimento dos profissionais tranquiliza os cuidadores e ajudam a encarar os problemas. Os pais são capacitados pela equipe de saúde sobre como fazer as atividades de estimulação motora, cognitiva e de linguagem em casa, fazendo com que leve para o seu dia a dia de forma lúdica e prazerosa, além de compartilhar experiências e dirimir dúvidas sobre a doença e o desenvolvimento do seu filho (BRASIL, 2016).

\section{CONCLUSÕES}

É de fundamental importância a articulação da família na extensão do seu domicílio para complementar as ações do fisioterapeuta e demais profissionais que acompanha esta criança. A família deve ter ação ativa na estimulação precoce da criança com microcefalia, através de estímulos táteis, auditivos, visuais, proprioceptivos, vestibulares, motores, e, também, ser encorajada a integrar-se a grupos de apoio à família, a fim de romper as barreiras do medo, angústia e da informação acerca do contexto que envolve seu 
filho. Mas estudos são necessários para avaliar o grau de comprometimento da família e cuidadores, além de estratégias para otimizar o desenvolvimento com qualidade dessas crianças com microcefalia.

\section{REFERÊNCIAS}

ABREU, T. T.; NOVAIS, M. C. M.; GUIMARÃES, I. C. B.. Crianças com microcefalia associada a infecção congênita pelo vírus Zika: características clinicas e epidemiológicas num hospital terciário. Revista de Ciências Médicas e Biológicas, Salvador, v.15, n.3, p.426-433, 2017. DOI: http://doi.org.10.9771/cmbio.v15i3.18347

BARBOSA, A. S. S.; SANTOS, L. S.; SANTANA, A. F. S. G.; MONTEIRO, L. F. T.. A participação da família no trabalho de reabilitação da criança com microcefalia. Revista Ciências Biológicas e da Saúde, Maceió, v.4, n.2, p.189-202, 2017.

BRASIL. Ministério da Saúde. Apoio psicossocial a mulheres gestantes, família e cuidadores de crianças com síndrome congênita por vírus Zika e outras deficiências: guia de práticas para profissionais e equipes de saúde. Brasília: MS, 2017.

BRASIL. Ministério da Saúde. Diretrizes de estimulação precoce: crianças de 0 a 3 anos com atraso no desenvolvimento neuropsicomotor. Brasília: MS, 2016.

BRASIL. Ministério da Saúde. Estimulação precoce da criança com microcefalia de $\mathbf{0}$ a $\mathbf{3}$ anos. Brasília: MS, 2017.

BRASIL. Ministério da Saúde. Protocolo de atenção à saúde e resposta à ocorrência de microcefalia relacionada à infecção pelo Zika Vírus. Brasília: MS, 2016.

DEFILIPO, E. C.; FRÔNIO, J. S.; TEIXEIRA, M. T. B.; LEITE, I. C. G.; BASTOS, R. R.; VIEIRA, M. T.; RIBEIRO, L. R..

Oportunidades do ambiente domiciliar para o

desenvolvimento motor. Saúde Pública, São Paulo, v.46, n.4, p.633-641, 2012.

DIAS, D. S.; VERORNEZ, M. H. G.. Direito à saúde e à educação das crianças microcéfalas. Unisanta Law and Social Science, Santos, v.6, n.2, p.145-162, 2017.

EICKMANN, S. H.; CARVALHO, M. D. C. G.; RAMOS, R. C. F.; ROCHA, M. A. W.; LINDEN, V. D.; SILVA, P. F. S.. Síndrome da infecção congênita pelo Zika Vírus. Caderno de Saúde Pública, Rio de Janeiro, v.32, n.7, p.1-3, 2016.
FLOR, C. J. D. V.; GUERREIRO, C. F.; MOTTA, J. L. A.. Desenvolvimento neuropsicomotor em crianças com microcefalia associado ao Zika Vírus. Revista Pesquisa em Fisioterapia, v.7, n.3, p.313-318, 2017. DOI: http://doi.org/10.17267/2238-2704rpf.v7i3.1386

FLORIANI, M. A. B.. O efeito Zika Vírus e suas implicações na educação infantil. Revista Maiêutica, Indaial, v.5, n.1, p.8387, 2017.

HALLAL, C. Z.; MARQUES, N. R.; BRACCIALLI, L. M. P. Aquisição de habilidades funcionais na área de mobilidade em crianças atendidas em um programa de estimulação precoce. Revista Brasileira de Crescimento e Desenvolvimento Humano, São Paulo, v.18, n.1, p.27-34, 2008.

REIS, J. C.; SANTOS, P. S.; BARRATA, M. F. O.; FALCÃO, I. V.. Abordagem da terapia ocupacional a bebê com microcefalia: uma experiência no estágio curricular. Revista Interinstitucional Brasileira de Terapia Ocupacional, Rio de Janeiro, v.2, n.1, p.212-227, 2018.

SÁ, F. E.; CARDOSO, K. V. C.; JUCÁ, R. V. B. M.. Microcefalia e Vírus Zika: do padrão epidemiológico à intervenção precoce. Revista Fisioterapia \& Saúde Funcional, Fortaleza, v.5, n.1, p.2-5, 2016.

SÁ, L. M. S. M. P. Intervenção Precoce e Microcefalia Estratégias de Intervenção Eficazes. Dissertação (Mestrado em Ciências da Educação) - Escola de Ensino Superior João de Deus, Lisboa, 2013.

SARI, F. L.; MARCON, S. S.. Participação da família no trabalho fisioterapêutico em crianças com paralisia cerebral. Revista Brasileira de Crescimento e Desenvolvimento Humano, São Paulo, v.18, n.3, p.220-239, 2008.

UNICEF. Fundo das Nações Unidas para a Infância. Orientações às famílias e aos cuidadores de crianças com alterações no desenvolvimento. Brasília: UNICEF, 2017.

A CBPC - Companhia Brasileira de Produção Científica (CNPJ: 11.221.422/0001-03) detém os direitos materiais desta publicação. Os direitos referem-se à publicação do trabalho em qualquer parte do mundo, incluindo os direitos às renovações, expansões e disseminações da contribuição, bem como outros direitos subsidiários. Todos os trabalhos publicados eletronicamente poderão posteriormente ser publicados em coletâneas impressas sob coordenação da Sustenere Publishing, da Companhia Brasileira de Produção Científica e seus parceiros autorizados. Os (as) autores (as) preservam os direitos autorais, mas não têm permissão para a publicação da contribuição em outro meio, impresso ou digital, em português ou em tradução. 